\title{
Natural Occupancy Shifts in Hotel Markets
}

Cornell Hospitality Quarterly $1-12$

(C) The Author(s) 2018

Reprints and permissions:

sagepub.com/journalsPermissions.nav DOI: 10.1 |77//9389655|8762837

journals.sagepub.com/home/cqx (S)AGE

\author{
Bram Gallagher' and Jack Corgel',2
}

\begin{abstract}
The natural occupancy rate underpins room price adjustment models for hotel market evaluations; however, models that assume that this rate is time invariant and everywhere constant may introduce error when forecasting future real room rates and benchmarking market strength. We use monthly STR room rate and occupancy data for five large U.S. metropolitan hotel markets to estimate natural occupancy differences in time and across markets. The notion of a timevarying natural occupancy aligns with changing market equilibrium. When aggregating over the entire sample, long-run average occupancy is reasonably good approximation of estimated constant natural occupancy. We use a Markov switching model to determine the likely equilibrium occupancy for unique periods in time, and these results inform Tse and Fischer's model to estimate time- and market-specific natural occupancy. Using the estimated natural occupancy rates for prevailing market regimes produces better fitting predictions than either constant natural occupancy or long-run average occupancy. Accordingly, they are most appropriate for practical applications.
\end{abstract}

\section{Keywords}

natural occupancy, rental adjustment, hotel market equilibrium

\section{Natural Occupancy as a Rate Mechanism in the Hotel Market}

The concept of equilibrium serves as the foundation for economic model construction and market analysis. Establishing a level of market equilibrium is at best an approximation, yet reasonably determined point estimates at which markets exhibit certain properties indicating balance between demand and supply can be helpful for market analysis. Another way to think about measured equilibrium is its real-world application as the benchmark for evaluating prevailing market conditions. The natural rate of unemployment, for example, is a well-known equilibrium principle in labor economics. It comes with various assumptions, although as a practical matter most economists would agree that the labor market reaches equilibrium in the United States at a rate falling between $3 \%$ and $5 \%$. In the event that the economy produces a rate outside of this range, it signals certain monetary and fiscal policy actions-simulative when the rate is relatively high and restrictive when low.

Hendershott's (1998) survey points to the many contributions from equilibrium modeling in real estate market research for improving prediction of rents, prices, and values. In the same way that the natural rate of unemployment provides an equilibrium reference point for analysis of labor markets, the natural vacancy rate, relative to the current vacancy rate, and indicates conditions in real estate markets. The idea of a natural rate of vacancy originated over six decades ago from studies of how residential rental (Blank \& Winnick, 1953; Eubank \& Sirmans, 1979; Rosen \& Smith, 1983; Smith, 1974) and office (Hekman, 1985; Shilling, Sirmans, \& Corgel, 1987) markets operate. The large volume of published work, commonly referred to as the "rental adjustment" literature, enhanced the understanding about how property rents adjust to equilibrium from states of disequilibrium.

Occupancy instead of vacancy rate measurement is the long-standing tradition in the hotel industry. ${ }^{1}$ According to natural rate theory as applied to hotel markets, in situations when lodging demand materially exceeds the supply of rooms, average daily rates (ADRs) rise to clear the shortage. Higher ADRs attract new supply to the market and discourage marginal guests, drawing occupancy back to the threshold natural occupancy rate. Current occupancy in an absolute sense does not directly impose market pressure on ADR. Instead, it is the difference between current occupancy and natural occupancy that matters. This differential represents excess demand, and the natural occupancy rate represents the long-run equilibrium capacity for hotel rooms

'CBRE Hotels' Americas Research, Atlanta, GA, USA

${ }^{2}$ Cornell University, Ithaca, NY, USA

\section{Corresponding Author:}

Bram Gallagher, CBRE Hotels' Americas Research, 3280 Peachtree

Road, NE, Suite 1400, Atlanta, GA 30305, USA.

Email: bram.gallagher@cbre.com 
to produce accommodation services in a market (Lee \& Jang, 2012).

Hotels compete with many alternative asset types for investment capital, but most closely with other forms of commercial real estate. Rents for leased real estate adjust to changes in vacancy although the adjustment speed is slowed by multiperiod tenancy, transaction costs associated with tenant turnover, and option value in rising markets (Grenadier, 1995). Property owners maintain the option to hold space in inventory during periods of increasing rents rather than lock into current rents for long periods; and they may not readily drop rents during periods of presumed temporary excess vacancy. This "inventory theory" helps explain long-run natural vacancy and the differences in natural vacancy rates across cities.

Hotels are subject to the same set of land rent and capital market conditions as other commercial property while short-term rental differentiates hotels from leased commercial property. Hotel management possesses the ability to reset rates for all but contracted (e.g., corporate and government) rooms on a daily basis in synchronization with inflation and market conditions. This makes the process of hotel rate adjustment considerably more dynamic and fluid than for property types with lease friction. ${ }^{2}$

With short-term rental, the option value of inventorying rooms equals zero. This means that the standard explanation for persistent vacancy (i.e., inventory theory) does not hold for hotels. Nevertheless, hotels universally run occupancies less than $100 \%$ and therefore the industry is in a constant state of overcapacity. Persistent overcapacity signified by double-digit, long-run average occupancy rates appears rooted in the influence of unexpected changes in demand on short-term rental rather than overbuilding (Lee \& Jang, 2012).

Because both hotels and leased properties experience persistent overcapacity, the methodology for modeling rental adjustment processes and estimating natural occupancy rates developed for the leased real estate markets is adaptable for hotel market analysis. Rosen and Smith (1983), Shilling et al. (1987), and Gabriel and Nothaft (1988) demonstrate that cities have constant natural vacancy rates that differ, and thus, the cross-sectional variation in rental market adjustment to equilibrium needs to be recognized. Recent studies of apartment and office markets find that natural vacancy rates are time varying (Tse \& Fischer, 2003) and subject to break points (Zhou, 2008). Zhou characterizes structural natural occupancy shifts as distinct from cyclical changes in that they are not merely deviations of the realized vacancy rate from its equilibrium, but rather long-lasting, unpredictable changes to the functional relationship between vacancy and rents.

The dynamic rate setting conditions endemic to hotel markets along with the potential for structural shifts give rise to estimating time-varying natural occupancy. Given the very different internal structures and exogenous factors affecting city hotel markets, cross-sectional patterns of time-dimensioned natural occupancy rates should be dissimilar. The size of the changes in natural occupancy over time may be meaningful. Wheaton and Torto (1988), for example, find that the natural vacancy rate for office space increased by $6 \%$ over an 18-year period from 1968 to 1986 . A comparably sized change, attributed to structural shifts, occurred in the Dublin office market after 1999 (McCartney, 2010). To our knowledge, hotel markets have not been examined in similar ways. If hotel markets are prone to structural shifts, then the natural occupancy rate from the most current regime has more relevance for market analysis than historic regimes and the long-run average occupancy rate.

We present modeled results to answer a variety of questions about hotel equilibrium occupancy. Is the estimated natural rate of occupancy constant or variable over time and across local markets? If sizable differences appear, why do these differences exist? Do the various methods for estimating natural occupancy generate similar results?

We find that hotel market natural occupancy varies over time and can be econometrically divided into distinct periods. We conclude that using the most recent period to guide decision making has advantages over using long-run averages that give equal weighting to every historic outcome. Our approach recognizes past equilibriums in determining the current equilibrium occupancy condition.

Revenue managers, hotel developers, and investors can interpret this time-varying natural occupancy as continuous periods where comparatively higher or lower occupancies signal market disequilibrium and warrant room rate changes. A decrease in search costs and market friction in hotels due to technological improvements, changing customer characteristics, and online travel agency (OTA) activity may produce permanently higher natural occupancy, suggesting that future estimates of change in real ADR should not rely on older, historical relationships between occupancy and ADR. Rather, the estimated relationship from the most current regime should be identified. Given the persistence of local regime states, the most recent natural occupancy regime represents the best approximation as to the relationship between occupancy and ADR for future periods.

The remainder of the article has the following organization. The section "Literature Review" contains a review of literature-its relevance and findings. In the section "Natural Occupancy Estimation: Constant and Varying," we present a model that incorporates our model and sets up empirical testing. The section "Data and Results" describes the data, explains variable construction, and presents results. The methodology and econometric issues discussion are found in this section. Concluding remarks appear in the final section. 


\section{Literature Review}

The intellectual motivation for studies of rent behavior beginning with the Blank and Winnick (1953) theoretical model has been to advance the stock of knowledge about how real estate markets operate. Repeated references appear in this literature regarding the unique aspects of these markets - sometimes referred to as "frictional responses" or simply frictions (Chau \& Wong, 2016). Long-term leases create substantial friction to rent adjustment, but rent stickiness also comes from transaction costs (e.g., agent fees), search costs involved in matching space owners and occupants, information asymmetry across owners and occupants, and slow supply responses (Englund, Gunnelin, Hendershott, \& Soderberg, 2008; Rosen \& Smith, 1983). Chau and Wong (2016) find that information asymmetry affects rental adjustment differentially for high- and low-end offices, being less important for high-end offices. A related research stream uses rental adjustment models for demand shock stress testing. Ibanez and Pennington-Cross (2013), for example, find that office rents adjust more slowly than industrial flex space rents following demand shocks.

Not only are the frictions in hotel markets stemming from leases almost nonexistent relative to other property types, but also online booking innovations have rendered transaction costs, search costs, and information asymmetry frictions to historic low levels in the adjustment of ADRs to equilibrium. In certain markets, the emergence of sharing economy is altering the daily-accommodated demand for lodging and potentially the room rate adjustment mechanism.

\section{Long-Run Rental Adjustment Models}

Because vacancy is usually positive and serves as a barometer of demand and supply interaction, the vacancy rate serves to explain how rents change in various models of long-run rental adjustment. Smith (1974) first implemented a straightforward rental adjustment model of the form:

$$
\Delta R_{i t}=\gamma\left(v^{*}-v_{t-1}\right) .
$$

The market rent in this model adjusts according to the difference between the equilibrium or natural vacancy rate and the beginning period rate. The adjustment occurs each period at speed $\gamma$. Rosen and Smith (1983) demonstrate how $v^{*}$ can be calculated from the parameters of a linear model based on Equation 1 by making the simplifying assumption that $v^{*}$ is constant through time. ${ }^{3}$ They also show that city real estate markets can have meaningful cross-sectional differences in $v^{*}$ and that the differences are related to expected demand growth (i.e., higher growth areas have larger $v^{*}$ s).

Hendershott (1996) introduced a more general equilibrium model of long-run rental adjustment to include the differential between equilibrium rent and actual rent along with the vacancy term in Equation 1. This model is,

$$
\Delta R_{i t}=\gamma\left(v^{*}-v_{t-1}\right)+\beta\left(R^{*}-R_{t-1}\right) .
$$

The enhanced version of the rental adjustment model doubled the explanatory power in tests using both Sydney and London office market data (Hendershott, 1996; Hendershott, Lizieri, \& Macgregor, 2010).

\section{Reduced Form Long- and Short-Run Rent Equations}

The modeling approach just described is labeled by Hendershott, Macgregor, and White (2002) as U.S. style rental adjustment to equilibrium in contrast to the European style reduced form demand and supply equations. The reduced form model has been adapted to both long- and short-run office rental movements to equilibrium (Hendershott, Macgregor, \& Tse, 2002) and other commercial real estate (Ibanez \& Pennington-Cross, 2013). In the long-run version, rents adjust to changes in the economy and to the level of the occupied stock instead of from a relationship between the current and natural vacancy (occupancy). In Equation 3, the natural log of rents is modeled as the natural $\log$ of employment $E_{i t}$ (i.e., demand), plus the natural $\log$ of occupied stock, and an error term. ${ }^{4}$ The subscripts $i$ and $t$ stand for city and time, respectively. The occupied stock $\left[\left(1-v_{i t-1}\right) S_{i t}\right]$ is a hybrid of demand and supply effects. Empirical studies have not consistently found the expected positive sign on occupied stock, which set off a minor controversy. In addition, the endogenous contemporaneous vacancy necessitates the substitution of $v^{*}$ for $v_{i t}-1$ where $v^{*}$ is estimated in a separate autoregressive model (Ibanez \& Pennington-Cross, 2013). Finally, the rent equation yields implied price income elasticity.

$$
\operatorname{Ln} R_{i t}=\beta_{0}+\beta_{1} \operatorname{Ln} E_{i t}+\beta_{2} \operatorname{Ln}\left[\left(1-v_{i t}^{*}\right) S_{i t}\right]+u_{i t} .
$$

The short-run version of the reduced form model presented as Equation 4 resembles the long-run reduced form model except that as an error correction model (ECM) the differencing operator $\Delta$ is an error correction term estimated from lags; and a one-period lagged endogenous variable appears to allow for estimation of the short-run adjustment speed. ${ }^{5}$ Also, $v^{*}$ is city and time dimensioned (i.e., $v_{i t}^{*}$ ).

$$
\begin{gathered}
\operatorname{Ln} R_{i t}=\alpha_{0}+\alpha_{1} \Delta \operatorname{Ln} E_{i t}+\alpha_{2} \Delta \operatorname{Ln}\left[\left(1-v_{i t}^{*}\right) S_{i t}\right] \\
+\alpha_{3} u_{i t-1}+\alpha_{4} \Delta \operatorname{Ln} R_{t-1}+\epsilon_{i t} .
\end{gathered}
$$

\section{Studies of Hotel Markets and Rate Adjustment}

Not surprisingly, given the absence of lease frictions, hotel room rates adjust to equilibrium in response to occupancy. Wheaton and Rossoff (1998) construct a series of equations 
to determine the extent to which hotel markets move with the general economy. They generate encouraging, albeit weak, results related to the room rate and occupancy relationship. However, the data from much of the period under study are infected with numerous problems. Using the Rosen and Smith (1983) method, they estimate a constant natural occupancy rate of approximately 62\% (1969-1994).

Estimates of natural occupancy resulted from a study of the nation and 24 U.S. cities (deRoos, 1999). This analysis uses an improved data set and the Rosen and Smith (1983) model to find a constant natural occupancy rate for the nation of $62.7 \%$ (1987-1998). The city natural occupancies ranged from $56.4 \%$ to $75.9 \%$. The author demonstrates how knowledge of the natural occupancy rate can assist in identifying hotel markets with strong and weak development potential.

Lee and Jang (2012) compute a national natural occupancy rate of $65.1 \%$ (1987-2010) by estimating and taking the ratio of the effect of supply and demand changes in natural logs on ADR in natural logs. They estimate a nearly identical rate by taking the ratio of the geometric mean of demand (i.e., number of rooms sold) and the geometric mean of supply (i.e., number of rooms available) over a long period. Producing the arithmetic or geometric average of observed occupancy over time has merit, simplicity being one of the most obvious advantages. ${ }^{6}$ Yet, neither directly accounts for the interaction of room rate and occupancy. Long-run averages produce good estimates when the real ADR of a market is stable. Inversely, if a market is consistently in disequilibrium resulting in either increases or lowers the real ADR over time, the long-run average will express this disequilibrium by being lower or higher than the true natural occupancy rate. We report these measures along with our estimates for comparison.

\section{Natural Occupancy Estimation: Constant and Varying}

The natural occupancy rate estimated with a Rosen and Smith (1983) rental adjustment model is a simple linear relationship between occupancy and changes to ADR when the natural occupancy rate remains constant. Equation 5 makes the change in ADR equal to the difference between the actual occupancy $\left(O_{a}\right)$ and the natural occupancy $\left(O_{n}\right)$ and property operating expense growth $(C)$. Of these three variables, $O_{n}$ is a constant, and $\epsilon$ is random error:

$$
\Delta \mathrm{ADR}_{t}=\beta_{1}\left(O_{a t-1}-O_{n}\right)+\gamma C_{t}+\epsilon_{t} .
$$

A simplified assumption is made whereby inflation changes generally reflect the change in property operating costs (Wheaton \& Torto, 1988). Thus, adjusting both sides of Equation 5 for inflation using the national Consumer Price Index ${ }^{7}$ results in the following equation for change in real $\mathrm{ADR}(\triangle \mathrm{RADR})$ :

$$
\Delta \mathrm{RADR}_{t}=\beta_{0} O_{a t-1}+\zeta R_{t}+\mu_{s t}+\epsilon_{t} .
$$

The difference between lagged actual occupancy $\left(O_{a t-1}\right)$ and the natural occupancy $\left(O_{n}\right)$ can be thought of as excess demand or occupancy in excess of the natural capacity for hotels to provide lodging. We expect that hoteliers will respond to excess demand in the previous period by raising hotel room rates in the current period, and thus $\beta_{1}$ will be positive. On the contrary, when the lagged actual occupancy rate is equal to the natural rate, the right-hand side of Equation 6 collapses to the error term so that there is no pressure to change rental rates.

The natural occupancy rate arises from factors such as the variability of demand and search costs for guests. Rosen and Smith (1983) identify market heterogeneity and renter turnover as significant factors that affect natural occupancy differences across cities, theoretically by intensifying market friction to varying degrees. After estimating each market separately, they find as much as 17-point dispersion in natural vacancy rates in the rental housing market, partially explained by frictional factors.

Although it is usual and practical to assume that forces influencing equilibrium in rental markets remain stable over time, especially at fixed locations, institutional changes that increase adjustment speed to equilibrium in lodging markets have the potential to permanently alter the capacity of hotels within markets, and thus natural occupancy rates as well. Improvements in demand forecasting with greatly enhanced data quality during the past two decades help market participants better anticipate all but truly unforeseen demand shocks. OTAs that allow for easy comparison of rates and availability, for example, may lead to a larger and more stable base of customers who consistently pay lower rates. Using the past relationship between occupancy and rate to predict future ADR growth rates after permanent shifts would lead to overestimation of ADR.

Other factors may temporarily affect the relationship of lagged occupancy and changes in real ADR. Times of uncertainty, economic slowdown, or shrinking wealth might increase natural occupancy levels as demand flattens while hotel supply remains relatively fixed. These effects likely correspond with recession periods and reverse after the recession end.

Temporal instability in natural occupancy renders the model in Equation 6 insufficient for estimating the relationship between real ADR changes and occupancy, and predictions of future real ADR change will be inaccurate. A variation of the Rosen and Smith model suggested by Tse and Fischer (2003) allows the natural occupancy rate to vary by time, specifically by describing differences to the baseline natural occupancy rate in periods identified by dummy variables. This method provides separate estimates of natural occupancies for timed groups of observations. One drawback of applying this method, however, is that 
groupings must be specified ex ante. Tse and Fischer show that a model with varying natural occupancy produces better fitting estimates than a model that depends solely on linear, constant estimates.

\section{Methodology for Allowing Natural Occupancy to Vary}

Previous studies rely on different, distinct natural occupancy levels in defined periods, termed regimes, to obtain better model fit than unvarying natural occupancy. As the market moves from one period to another, a regime switch occurs that changes the equilibrium natural occupancy in that market. This technique has been applied in London apartments and U.K. office, retail, and industrial real estate markets (Farrelly \& Sanderson, 2005; Füss, Stein, \& Zietz, 2011). More recently, regime switching has been applied to long-run valuation in the Paris office market (Bruneau \& Cherfouh, 2015). Typically, the periods of the regime are defined using rules about sudden changes to occupancy or rent, meaning that the dominant regime is assumed to be known and observed in these models, as are the changes to the dominant regime.

To introduce a general framework to identify regime changes, we apply a Markov switching model to relationships between occupancy and change in real ADR. The model objectively identifies persistent structural changes in the relationships between variables and is particularly applicable when the true regime is not observed (Hamilton, $1989,1994)$. The same treatment can be applied to any market without developing market-specific rules; however, the number of possible states must be specified a priori. We specify two states for simplicity and because the two-state case produced the least ambiguous probabilities in testing. We designate the most frequent state as the baseline state and the periods that punctuate the baseline state with a higher equilibrium natural occupancy, and thus relatively low ADR change for the period's occupancy, the alternate natural occupancy state. Probabilities of a period being in either state are produced for every time period, and the market is assumed to be in the most likely state.

The obtained state variable from the Markov switching model then is introduced as the Tse-Fischer dummy for a time-varying natural occupancy model:

$$
\Delta \operatorname{RADR}_{t}=\beta_{1}\left(O_{a t-1}-O_{n}-\psi S_{t}\right)+\epsilon_{t},
$$

where $S$ takes on a value of zero for months under the baseline regime and one for months under the alternate natural occupancy regime. $\psi$ is an estimated parameter that shifts the natural occupancy during months when $S_{t}=1$. A built-in assumption of this specification is that the effect of excess demand, $\beta_{1}$, is the same across (and thus independent of) states. $\beta_{1}$ can be thought of as the speed of adjustment to market disequilibrium and is determined by hotel technology, consumer behavior, and producer expectations. Although changes to this adjustment speed could be modeled with changes to the natural occupancy rate, empirical tests of our data show that estimates of differences across states are small, often insignificant, and do not affect estimates of the natural occupancy rate. $\beta_{1}$ is made constant for the purposes of parsimony and ease of interpretation. The assumption of only two kinds of state, the baseline and the alternate natural occupancy states, implies that the natural occupancy rate can take on only two values: baseline and alternate.

Recessions represent exogenous shocks to the hotel market that should be isolated from structural shifts in how hotels operate (i.e., the natural occupancy rate). To obtain dates of state switching controlling for recessionary periods, a Markov switching model is first estimated with National Bureau of Economic Research recession periods as a vector of independent dummy variables $R$ :

$$
\Delta \operatorname{RADR}_{t}=\beta_{0} O_{a t-1}+\zeta \boldsymbol{R}_{t}+\mu_{s t}+\epsilon_{t} .
$$

In addition, the months during the 1996 Olympic Games are given dummy variables when estimating (Equation 8) for Atlanta. The probability estimates from this model are used to define periods of changing natural occupancy. Recession dummies are also added to Equation 7 to separate recession effects from structural changes to natural occupancy:

$$
\Delta \operatorname{RADR}_{t}=\beta_{1}\left(O_{a t-1}-O_{n}-\psi s_{t}-\zeta \boldsymbol{R}_{t}\right)+\epsilon_{t} .
$$

The natural occupancy levels are then estimated using nonlinear least squares on Equation 9.

\section{Data and Results}

We examine monthly occupancy and ADR data from STR for hotels in Atlanta, Chicago, New York, Los Angeles, and Washington, D.C., over the period January 1988-March 2017. These data are broadly divided by STR chain scale categories into two groups. The upper priced group is comprised of hotels in the upscale, upper upscale, or luxury chain scales, whereas the lower priced group includes hotels in the economy, midscale, and upper midscale chain scales. Each group in each market constitutes a separate time series of 351 periods. Nominal ADRs are adjusted to real values. Finally, our analysis involves time series of observations from the top 60 U.S. hotel markets and five geographically diverse city markets-Atlanta, Chicago, Los Angeles, New York, and Washington, D.C.

The raw data show that New York experienced a shift in the relationship between real ADR and occupancy since 2010 that may represent a change in the underlying natural occupancy rate. Notably, real ADR remains flat then declines 


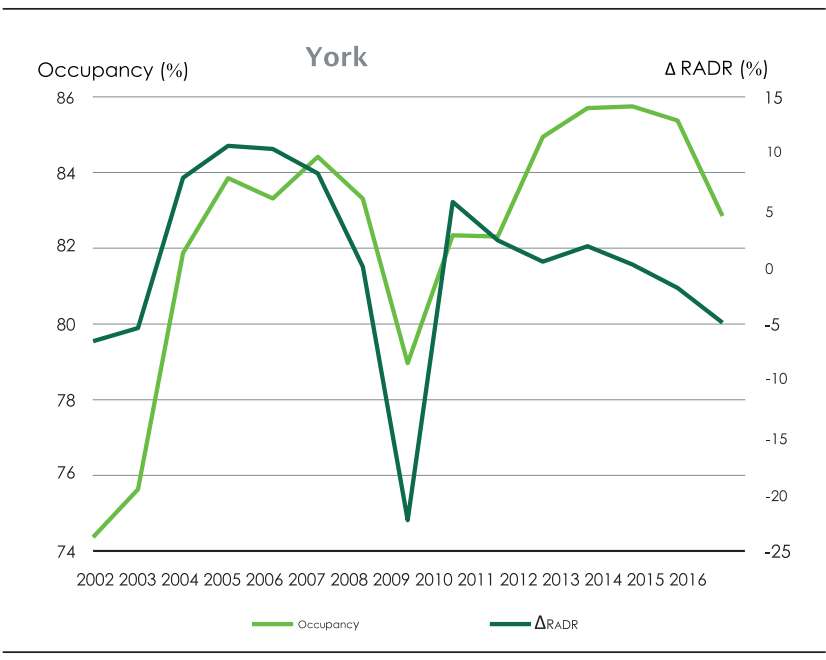

Figure 1.

Occupancy and Change in Real ADR in New York. Source. CBRE Hotels, STR, Inc. Q3 2016.

Note. $A D R=$ average daily rate. $\triangle R A D R=$ change in real $A D R$.

as occupancy increases, as shown in Figure 1. Even as occupancy in New York reached record highs in 2014, real ADR weakened, and then begins to fall. A close relationship exists between occupancy and real ADR change in Chicago (see Figure 2) until 2013, when occupancy continues to increase as real ADR stalls. Los Angeles (see Figure 3) experienced real ADR growth outpacing occupancy. All markets recorded abrupt decreases to occupancy and real ADR growth at the wake of the financial collapse in 2008. Although several alternative explanations have been suggested for observed shifts in the ADR and occupancy relationship including the increasing prominence of sharing economy lodging alternatives, competition between OTAs, and rapid supply growth partially funded by nonmarket government programs such as EB5, the timing of any shifts in the natural occupancy rate may provide evidence about which of these are most important and whether a regime switch is either temporary or permanent. The direction of the change in natural occupancy also indicates whether a constant model will over- or underestimate change to real ADR.

We use nonlinear least squares so that the parameters of the rental adjustment model as described in Equation 6can be directly estimated. ${ }^{8}$ To account for seasonality, the trailing 12-month moving average of occupancy rate is used as the lagged occupancy rate. For direct comparison, recession dummies are also used when obtaining constant natural occupancy. Resulting constant natural occupancy rate estimates are described in Table 1 along with long-run arithmetic and geometric averages of occupancy for comparison. Standard errors, $R^{2}$ values, and root mean squared errors (RMSEs) are presented in Table 2.

Imposing the assumption that the natural occupancy rate is constant over time produces disparate natural occupancy

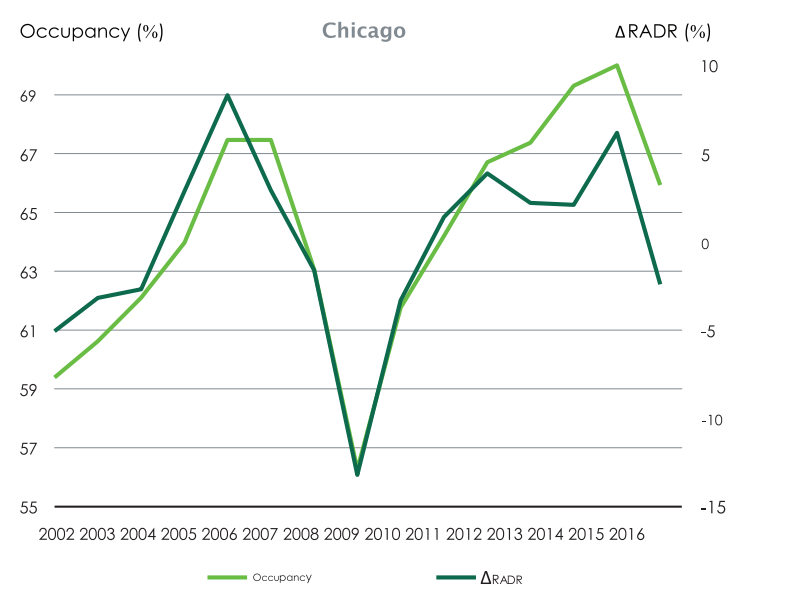

Figure 2.

Occupancy and Change in Real ADR in Chicago.

Source. CBRE Hotels, STR, Inc. Q3 2016.

Note. $A D R=$ average daily rate. $\triangle R A D R=$ change in real $A D R$.

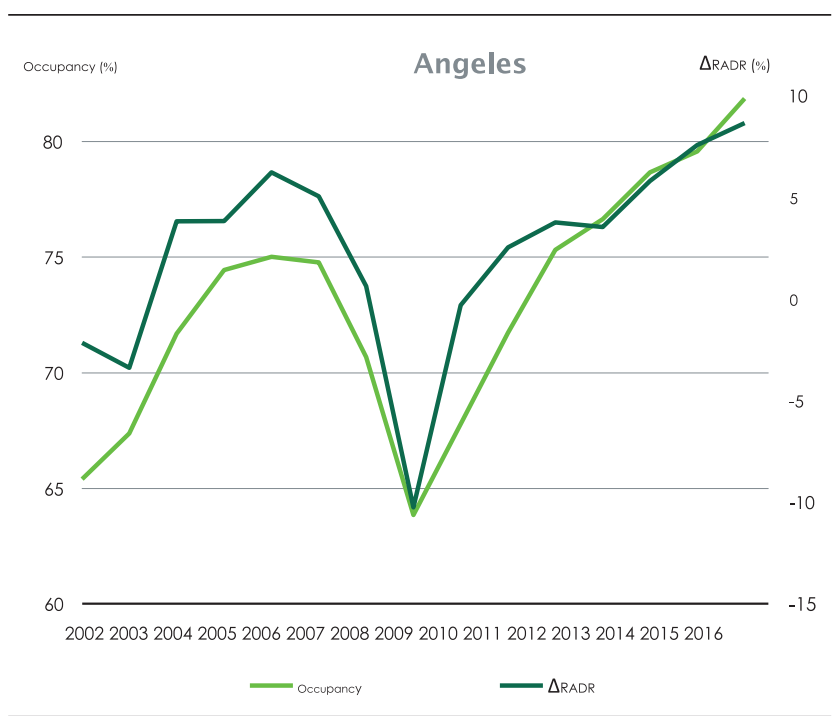

Figure 3.

Occupancy and Change in Real ADR in Los Angeles.

Source. CBRE Hotels, STR, Inc. Q3 2016.

Note. $\mathrm{ADR}=$ average daily rate. $\triangle \mathrm{RADR}=$ change in real $\mathrm{ADR}$.

estimates across markets. In New York, for example, lower priced hotels have a natural occupancy between 13 and 14 percentage points higher than in Atlanta. Occupancy of $72 \%$ would lead to significant increase to the Atlanta lower priced ADR but would have a strong negative effect on ADR in New York lower priced hotels. Long-run arithmetic averages are an excellent approximation in cities where real ADR over time is relatively constant, such as Chicago or Atlanta upper priced. For Chicago and Atlanta lower priced segments, natural occupancies are higher than the long-run arithmetic and geometric averages, and real ADR has been 
Table 1.

Constant Natural Occupancies Across Cities, 1988m I-2017m3.

\begin{tabular}{lcccccc}
\hline & Top 60 Markets & Atlanta & Chicago & Los Angeles & New York & Washington, D.C. \\
\hline Lower priced hotels & & & & & & \\
$\quad$ Natural occupancy & 61.5 & 60.7 & 61.6 & 65.2 & 76.3 & 63.9 \\
Arithmetic mean occupancy & 62.7 & 60.1 & 61.3 & 66.8 & 78.5 & 63.9 \\
Geometric mean occupancy & 61.7 & 59.6 & 60.4 & 66.3 & 77.8 & 62.8 \\
Real ADR change & 0.00 & -0.30 & -0.47 & 0.13 & 0.57 & -0.24 \\
Upper priced hotels & & & & & & \\
Natural occupancy & 67.5 & 66.5 & 68 & 69.4 & 76.9 & 69.9 \\
Arithmetic mean occupancy & 69.73 & 66.65 & 68.45 & 72.615 & 80.2 & 70.35 \\
Geometric mean occupancy & 68.9 & 66.2 & 67.4 & 72.2 & 79.8 & 69.5 \\
Real ADR change & 0.4 & 0.0 & 0.0 & 1.3 & 0.4 & 0.3 \\
\hline
\end{tabular}

Source. CBRE Hotels' Americas Research, STR Q3 2017.

Note. $A D R=$ average daily rate.

Table 2.

Constant Natural Occupancy Estimates.

\begin{tabular}{|c|c|c|c|c|c|c|}
\hline & Top 60 Markets & Atlanta & Chicago & Los Angeles & New York & Washington, D.C. \\
\hline \multicolumn{7}{|l|}{ Lower priced hotels } \\
\hline \multirow{2}{*}{ Excess demand $\left(\beta_{\mathrm{I}}\right)$} & $0.307^{*}$ & $0.530 *$ & $0.709 *$ & $0.469 *$ & $0.50 I^{*}$ & $1.024 *$ \\
\hline & $(0.007)$ & $(0.033)$ & $(0.051)$ & $(0.032)$ & $(0.060)$ & $(0.077)$ \\
\hline \multirow[t]{2}{*}{ Natural occupancy $\left(O_{n}\right)$} & $0.615^{*}$ & $0.607^{*}$ & $0.616^{*}$ & $0.652 *$ & $0.763 *$ & $0.639 *$ \\
\hline & $(0.001)$ & $(0.005)$ & $(0.003)$ & $(0.005)$ & $(0.009)$ & $(0.002)$ \\
\hline$R^{2}$ & .18 & .53 & .35 & .43 & .18 & .45 \\
\hline RMSE & 0.050 & 0.044 & 0.041 & 0.035 & 0.077 & 0.034 \\
\hline \multicolumn{7}{|l|}{ Upper priced hotels } \\
\hline \multirow[t]{2}{*}{ Excess demand $\left(\beta_{1}\right)$} & $0.382 *$ & $0.888^{*}$ & $1.075^{*}$ & $0.586 *$ & $0.422 *$ & I.159* \\
\hline & $(0.0114)$ & $(0.0633)$ & $(0.0793)$ & $(0.0409)$ & $(0.0662)$ & $(0.1709)$ \\
\hline \multirow[t]{2}{*}{ Natural occupancy $\left(O_{n}\right)$} & $0.675^{*}$ & $0.665^{*}$ & $0.680^{*}$ & $0.694 *$ & $0.769 *$ & $0.699 *$ \\
\hline & $(0.002)$ & $(0.003)$ & $(0.003)$ & $(0.005)$ & $(0.011)$ & $(0.003)$ \\
\hline$R^{2}$ & .20 & .52 & .48 & .44 & .20 & .20 \\
\hline RMSE & 0.056 & 0.052 & 0.046 & 0.041 & 0.077 & 0.056 \\
\hline$n$ & 22,028 & 351 & 351 & 351 & 351 & 351 \\
\hline
\end{tabular}

Source. CBRE Hotels' Americas Research, STR Q3 2017.

Note. RMSE = root mean squared error.

$* p<.001$.

declining. Los Angeles has a natural occupancy below its long-run averages, and its real ADR has been increasing. The geometric mean does not differ from the arithmetic greatly across city markets and is 30 to 100 basis points lower than the estimated constant natural occupancy. The arithmetic mean, on the contrary, more accurately predicts long-run changes to ADR when differenced from the estimated constant natural occupancy rate.

All parameters are estimated with a high degree of precision, exceeding the $0.1 \%$ significance level. Constant natural occupancy estimates range from $60 \%$ to $77 \%$. Not only does natural occupancy vary across geography, but it also varies within markets depending on chain scale grouping. Estimates are universally higher in upper priced hotels compared with the lower priced in the same market, although in New York the difference is within the standard errors. The effect of excess demand on real ADR, or $\beta$, is estimated to be between approximately 0.5 and proportionate among specific markets, but is especially low in the top 60 markets specification, likely due to the aggregation. This means that for a percent increase in occupancy above the natural occupancy rate, real ADR can be expected to rise $0.5 \%$ in New York lower priced hotels, $1.1 \%$ in Chicago upper priced hotels, and $0.4 \%$ in upper priced hotels on average in the 60 markets.

Model fit for the constant natural occupancy is varied. The best fit is achieved in Atlanta lower priced, where $R^{2}$ exceeds $50 \%$. The lowest RMSE is achieved in Los Angeles lower 
Table 3.

Stopping and Starting Dates for Alternate Natural Occupancy States.

\begin{tabular}{|c|c|c|c|c|c|c|c|c|}
\hline & \multicolumn{2}{|c|}{ Regime I } & \multicolumn{2}{|c|}{ Regime 2} & \multicolumn{2}{|c|}{ Regime 3} & \multicolumn{2}{|c|}{ Regime 4} \\
\hline & Start & Stop & Start & Stop & Start & Stop & Start & Stop \\
\hline \multicolumn{9}{|l|}{ Lower priced hotels } \\
\hline Atlanta & Began prior & $1992 \mathrm{mlO}$ & $1996 \mathrm{~m} 9$ & $2002 \mathrm{~m} 9$ & $2008 \mathrm{mII}$ & $2010 \mathrm{mII}$ & & \\
\hline Chicago & Began prior & 1996m6 & $2000 \mathrm{~m} 2$ & 2004m7 & $2008 \mathrm{mII}$ & $2010 \mathrm{mlO}$ & $2016 \mathrm{ml}$ & Ongoing \\
\hline Los Angeles & Began prior & 1993m8 & $2001 \mathrm{mll}$ & $2004 \mathrm{~m} 2$ & $2009 \mathrm{~m} 3$ & $2010 \mathrm{~m} 9$ & $2017 \mathrm{~m} 2$ & Ongoing \\
\hline New York & & & $200 \mathrm{Imll}$ & $2002 \mathrm{mlO}$ & $2008 \mathrm{~m} / 2$ & $2010 \mathrm{~m} 3$ & $2013 \mathrm{~m} \mid \mathrm{I}$ & Ongoing \\
\hline Washington, D.C. & Began prior & $1992 \mathrm{~m} 2$ & $2000 \mathrm{~m} 5$ & $2002 m 8$ & $2008 \mathrm{~m} 3$ & $2010 \mathrm{~m} 3$ & & \\
\hline \multicolumn{9}{|l|}{ Upper priced hotels } \\
\hline Atlanta & & & $1996 \mathrm{~m} 9$ & $2004 m 4$ & $2008 \mathrm{~m} 5$ & $2010 \mathrm{~m} 7$ & $20 \mid 4 \mathrm{ml}$ & Ongoing \\
\hline Chicago & 1989m I & $1992 \mathrm{mII}$ & 1999m4 & $2004 \mathrm{mll}$ & $2009 m 4$ & $2010 \mathrm{~m} 6$ & $2013 \mathrm{~m} 2$ & Ongoing \\
\hline Los Angeles & & & & & & & $2013 m 8$ & $2015 \mathrm{~m} 2$ \\
\hline New York & 1990m8 & $1991 \mathrm{~m} / 2$ & $2001 \mathrm{mlO}$ & $2003 \mathrm{mlO}$ & $2008 \mathrm{~m} / 2$ & $2010 \mathrm{~m} 5$ & $2011 \mathrm{~m} / 2$ & Ongoing \\
\hline Washington, D.C. & & & & & $2008 \mathrm{~m} 3$ & Ongoing & & \\
\hline
\end{tabular}

Source. CBRE Hotels' Americas Research, STR Q3 2017.

priced. The top markets goodness of fit is relatively low due to the heterogeneity of the markets; however, New York has comparably low $R^{2}$ values, with only $18 \%$ to $20 \%$ of the variation in change to real ADR explained with a constant natural occupancy model. New York also has significantly higher RMSE than other markets and the top markets aggregate. It may be that New York is particularly poorly described by a model that restricts natural occupancy to a constant. This could be due to more frequent switching or a larger difference between the natural occupancy rates of the states.

\section{Time-Varying Natural Occupancy Estimation}

Next, we introduce the time-varying model. A Markov switching model on data with recession effects included as control variables produces probabilities for the two states for each of the two price tiers of the five markets, and the market is assumed to be in the most likely state. All tiers achieved a high degree of persistence in their baseline states, defined as the likelihood greater than $90 \%$ of the next period state being the same as the current state. Four general periods of the alternate natural occupancy state, which we call "regimes," are identified, each representing different equilibrium conditions and thus a different equilibrium occupancy solution for the hotel market. The first begins sometime before the sample and ends in the early nineties. The second begins around the turn of the millennium and ends between 2002 and 2004. The third coincides with the aftermath of the Great Recession, beginning in 2008-2009 and ending in 2010. The fourth regime starts at different points, depending on group and market, but ranges from 2012 to 2016 to not yet having occurred. New York upper priced hotels entered Regime 4 early, less than 2 years after recovering from the Great Recession.
The state variables produced by the switching model are introduced as the dummy variable in Equation 9, which is estimated by nonlinear least squares. Table 3 reports estimated natural occupancy break points for the alternate natural occupancy regime periods. The timing of the regimes for New York upper priced and Chicago lower priced is illustrated in Figures 4 and 5. Table 4 summarizes the results ${ }^{9}$ when adding the obtained state as the dummy variable.

As with the constant natural occupancy model, all parameters are estimated with a high degree of precision. The effect of excess demand is mixed for the markets compared with the constant natural occupancy estimates-New York has an increased effect, whereas Chicago, Atlanta, and Los Angeles lower priced have a smaller effect. Goodness of fit markedly improves for all markets in both tiers. Most dramatic is New York, with an increase of $R^{2} 3$ times as high compared with a constant natural occupancy and RMSE approximately a third smaller. On average, $R^{2}$ for the constant natural occupancy is $35 \%$ and for the time-varying natural occupancy is $58 \%$. RMSE for the constant natural occupancy is an average 5\% and for the time-varying occupancy is $4 \%$. The largest gains in fit, New York upper priced, are accompanied by large estimates for the effect of the alternate state. DC upper price, in contrast, has a modest gain in fit and a relatively small change in natural occupancy during the alternate state.

Another implication of these results is that the baseline natural occupancy is somewhat lower than previously estimated. Whereas the constant natural occupancy averaged $67.8 \%$, the baseline natural occupancy in the state-varying model is $64.8 \%$. In addition, the average boost to the natural occupancy rate in the alternate state is $9.6 \%$. On average, natural occupancy in the constant natural occupancy rate model is higher than the baseline of the time-varying model, 


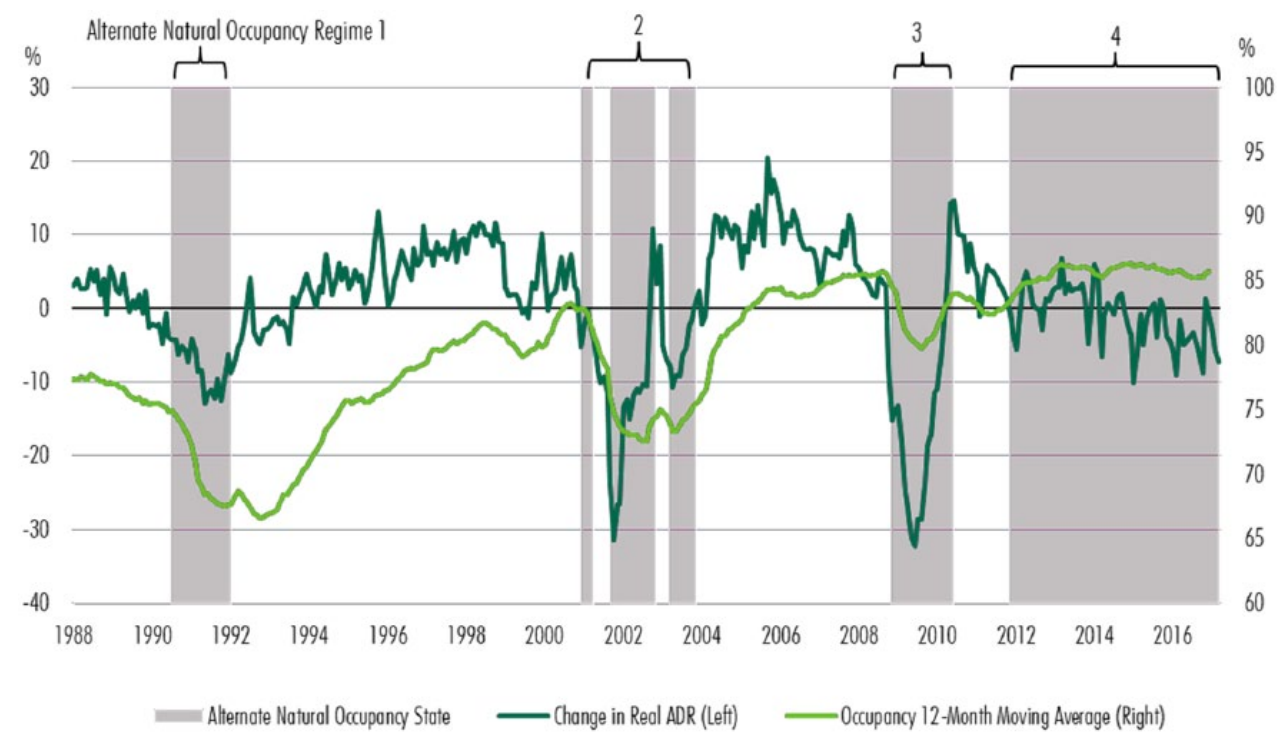

Figure 4.

Change in Real ADR, Occupancy, and States, New York Upper.

Source. CBRE Hotels, STR Inc. Q3 2017.

Note. $A D R=$ average daily rate.

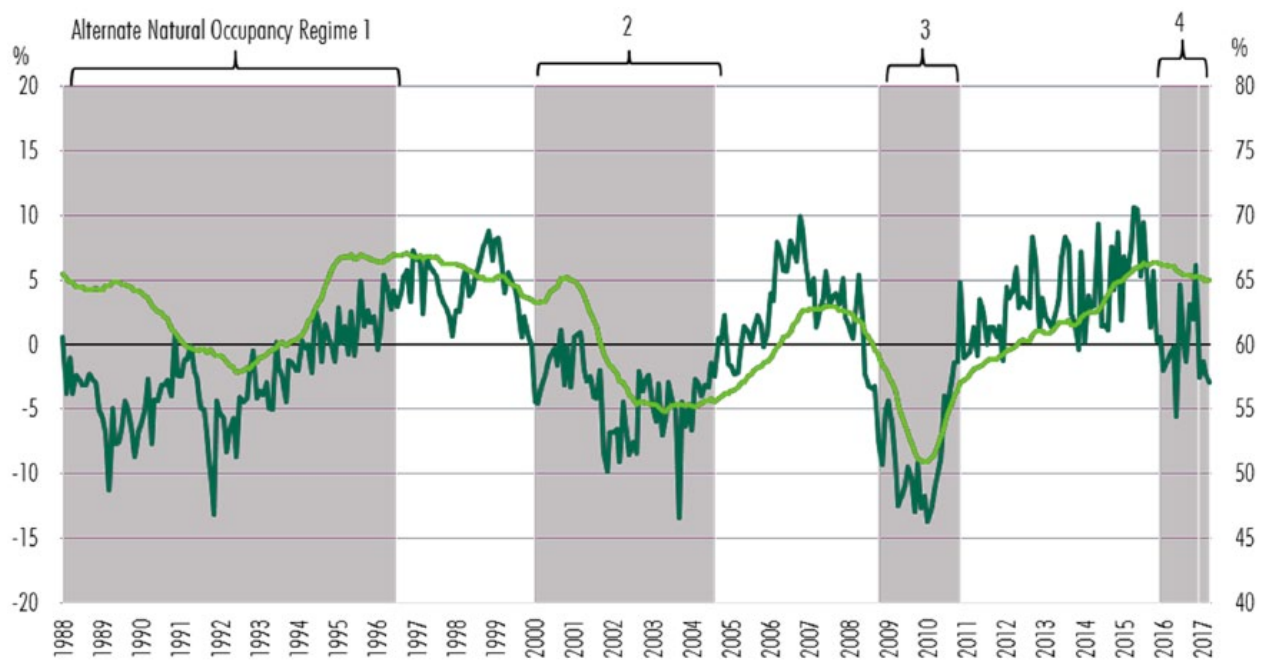

Alternate Natural Occupancy State —Change in Real ADR (Left) —Occupancy 12-Month Moving Averoge (Right)

\section{Figure 5.}

Change in Real ADR, Occupancy, and States, Chicago Lower.

Source. CBRE Hotels, STR Inc. Q3 2017.

Note. $A D R=$ average daily rate.

but lower than in the alternate state of the time-varying model.

The frequency and duration of alternate natural occupancy periods are generally decreasing in time for the lower priced hotels, with the notable exception of New York, whereas they are increasing in the upper priced hotels. As the baseline natural occupancy for lower price hotels $(61.6 \%)$ are lower than upper price hotels $(68 \%)$, the realized natural occupancies (i.e., baseline natural occupancy plus the elevated state coefficient when in the elevated state) of upper- and lower-price hotels are, on average, diverging over time. Atlanta and DC lower price hotels, for 
Table 4.

State-Varying Natural Occupancy.

\begin{tabular}{lccccc}
\hline & Atlanta & Chicago & Los Angeles & New York & Washington, D.C. \\
\hline Lower priced hotels & & & & & \\
Excess demand $\left(\beta_{1}\right)$ & $0.421^{*}$ & $0.529^{*}$ & $0.37 I^{*}$ & $0.724^{*}$ & $0.99 I^{*}$ \\
& $(0.032)$ & $(0.040)$ & $(0.028)$ & $(0.055)$ & $(0.065)$ \\
Natural occupancy $\left(O_{n}\right)$ & $0.566^{*}$ & $0.556^{*}$ & $0.605^{*}$ & $0.727^{*}$ & $0.628^{*}$ \\
& $(0.005)$ & $(0.007)$ & $(0.008)$ & $(0.006)$ & $(0.002)$ \\
Alternate state $(\psi)$ & $0.121^{*}$ & $0.117^{*}$ & $0.133^{*}$ & $0.169^{*}$ & $0.048^{*}$ \\
& $(0.017)$ & $(0.012)$ & $(0.016)$ & $(0.013)$ & $(0.005)$ \\
$R^{2}$ & .67 & .68 & .65 & .53 & .62 \\
RMSE & 0.037 & 0.029 & 0.028 & 0.059 & 0.028 \\
Upper priced hotels & & & & $0.735^{*}$ & $1.287^{*}$ \\
Excess demand $\left(\beta_{1}\right)$ & $0.962^{*}$ & $0.981^{*}$ & $0.615^{*}$ & $(0.052)$ & $0.164)$ \\
& $(0.057)$ & $(0.069)$ & $(0.041)$ & $0.718^{*}$ & $0.689^{*}$ \\
Natural occupancy $\left(O_{n}\right)$ & $0.648^{*}$ & $0.658^{*}$ & $0.686^{*}$ & $(0.006)$ & $(0.003)$ \\
& $(0.003)$ & $(0.004)$ & $(0.004)$ & $0.162^{*}$ & $0.033^{*}$ \\
Alternate state $(\psi)$ & $0.036^{*}$ & $0.044^{*}$ & $0.095^{*}$ & $(0.011)$ & $(0.008)$ \\
$R^{2}$ & $(0.006)$ & $(0.006)$ & $(0.015)$ & .62 & .30 \\
RMSE & .57 & .59 & .55 & 0.053 & 0.052 \\
$n$ & 0.049 & 0.041 & 0.037 & 351 & 351 \\
\hline
\end{tabular}

Source. CBRE Hotels' Americas Research, STR Q3 2017.

Note. RMSE = root mean squared error.

$*_{p}<.001$.

instance, have been in the baseline state since the end of the Great recession. Chicago lower price entered Regime 4 of the elevated state in 2016, and Los Angeles entered Regime 4 only in 2017 , assuming that the elevated state persists and is not merely an anomaly.

On the contrary, upper price hotels enter Regime 4 soon after the Great Recession or, in the case of DC, immediately after. New York enters Regime 4 in 2011, Chicago and Los Angeles in 2013, and Atlanta in 2014. New York lower price hotels also enter Regime 4 relatively early, in 2013. In four cities (Atlanta, Chicago, New York, and DC), upper price hotels remain in the elevated state. In Atlanta, Chicago, and DC, ADR will not rise unless occupancy is $3 \%$ to $4.4 \%$ higher than the baseline occupancy that would otherwise trigger rate increases. For Los Angeles, the elevated state coefficient is higher at around 10 percentage points. New York upper price hotels see natural occupancy above 16\% higher than baseline since 2012 .

\section{Implications for Hotel Revenue Managers, Developers, and Investors}

Occupancy is a key driver of hotel performance forecasting; however, care must be taken when extending the relationship between occupancy and real ADR. Changes to ADR are created by departures of realized occupancy from the equilibrium natural occupancy, so changes in either the realized occupancy in a market or factors that affect the equilibrium rate also change ADR. Intrinsic differences in markets lead to very different outcomes for similar occupancies. Estimating the effect of occupancy separately for each market captures the different effects, but a more complex problem is time-varying natural occupancies. Models using constant natural occupancy as an implied assumption produce consistently biased forecasts in the presence of time-varying natural occupancy.

Revenue managers, hotel developers, and investors should interpret time-varying natural occupancy as continuous periods when comparatively higher or lower occupancies signal market disequilibrium and warrant room rate changes. These periods are unique to what has happened in the general economy reflected in the business cycle. Moreover, decreases in search costs and market frictions in hotels due to technological improvements, changing customer characteristics, and OTA activity could produce permanently higher natural occupancy, suggesting that future estimates of $\triangle$ RADR should not rely on older, historical relationships between occupancy and ADR. Rather, the estimated relationship from the most current regime should be applied. Given the local persistence in the regime states, the most recent natural occupancy regime represents the best approximation as to the relationship between occupancy and ADR for future periods. 
Separate explanations could potentially explain similar changes to natural occupancy. While the period of elevated natural occupancy that occurred from 2008-2010 could be attributed to uncertainty and consequent demand flattening that occurred as a result of the financial collapse and Great Recession, no comparable recessionary pressure was exerted in New York starting in 2012 or in the other cities after 2013. These trends also are highly market specific. New York, while reaching record occupancy in Q2 2014 and maintaining high occupancies since, is still experiencing diminishing or flat ADR. This signals that the hotel market in New York is either oversupplied with rooms or at equilibrium. Los Angeles, on the contrary, has an increasing occupancy along with a declining natural occupancy, signaling that the market is undersupplied and that rates should continue rising.

Hotel management teams have day-to-day interests in metrics that assist in room rate setting. From a financial capital perspective, deRoos (1999) emphasizes how knowledge of the natural occupancy rate assists in identifying hotel markets with strong and weak development potential. The natural occupancy rate can play an important role in capital allocation decisions by equity and debt capital suppliers involved in a variety of hotel real estate transactions. Our contribution deepens the understanding of the crosssectional and time-varying properties of the natural occupancy rate.

\section{Declaration of Conflicting Interests}

The author(s) declared no potential conflicts of interest with respect to the research, authorship, or publication of this article.

\section{Funding}

The author(s) received no financial support for the research, authorship, or publication of this article.

\section{Notes}

1. The occupancy percent usually equals one minus the vacancy rate. An exception to this identity would occur, for example, when "shadow" or "hidden" vacancy is not recognized and accounted for in the vacancy calculation. Shadow and hidden vacancy relates to sublet office spaces occupied by tenants paying below market or no rent (see Englund, Gunnelin, Hendershott, \& Soderberg, 2008).

2. Also, the rate adjustment process slows down when opportunities exist to book higher paying transit guest near check-in dates and forgo lower rate group and transit business, which is characterized by longer booking lead times. This feature of hotel markets becomes most evident during periods of high demand.

3. Given the model $\Delta R_{\mathrm{it}}=\beta_{0}+\beta_{1} \mathrm{v}_{t-1}+e_{\mathrm{it}}$, and the assumption that the natural rate is embedded into the constant term, $v^{*}$ is computed as $\beta_{0} / \beta$.

4. Prior steps to Equation 3 intentionally skipped. See Ibanez and Pennington-Cross (2013) for full development.
5. The usual cointegration and stationary requirements apply.

6. Calculating the breakeven occupancy or the occupancy rate when profit equals zero provides another perspective although one not well aligned with the notion of equilibrium unless the zero excess profit amount is determinable.

7. Correlations were calculated for all metro-level CPIs and national CPI and were found to be in excess of $99 \%$. For simplicity, national CPI is used wherever average daily rate (ADR) is adjusted for inflation.

8. This method produces coefficient estimates for $\beta_{1}$ and $O$ equivalent to the results of the ordinary least squares (OLS) specification described in Rosen and Smith (1983). All reported standard errors are Huber-White heteroscedasticityrobust, and observations are weighed by rooms.

9. The obtained results are produced using the same nonlinear least squares procedure employed for constant natural occupancy except with the addition of $\psi$ and $\zeta$.

\section{References}

Blank, D. M., \& Winnick, L. (1953). The structure of the housing market. Quarterly Journal of Economics, 67, 181-203.

Bruneau, C., \& Cherfouh, S. (2015). Long-run equilibrium for the greater Paris office market and short-run adjustments. Journal of Property Research, 32, 301-323.

Chau, K. W., \& Wong, S. K. (2016). Information asymmetry and the rent and vacancy rate dynamics in office markets. The Journal of Real Estate Finance and Economics, 53, 162-183.

deRoos, J. A. (1999). Natural occupancy rates and development gaps: A look at the U.S. lodging industry. Cornell Hotel and Restaurant Administration Quarterly, 40, 14-22.

Englund, P., Gunnelin, A., Hendershott, P. H., \& Soderberg, B. (2008). Adjustment in property space markets: Taking long-term leases and transaction costs seriously. Real Estate Economics, 36, 81-109.

Eubank, A. A., \& Sirmans, C. F. (1979). The price adjustment mechanism for rental housing in the United States. Quarterly Journal of Economics, 93, 163-183.

Farrelly, K., \& Sanderson, B. (2005). Modelling regime shifts in the city of London office rental cycle. Journal of Property Research, 22, 325-344.

Füss, S., Stein, M., \& Zietz, J. (2011). A regime-switching approach to modeling rental prices of U.K. real estate sectors. Real Estate Economics, 40, 317-350.

Gabriel, S. A., \& Nothaft, F. E. (1988). Rental housing markets and the natural vacancy rate. Journal of the American Real Estate and Urban Economics Association, 16, 419-429.

Grenadier, S. R. (1995). Valuing lease contracts a real-options approach. Journal of Financial Economics, 38, 297-331.

Hamilton, J. D. (1989). A new approach to the economic analysis of nonstationary time series and the business cycle. Econometrica, 57, 357-384.

Hamilton, J. D. (1994). Time series analysis. Princeton, NJ: Princeton University Press.

Hekman, J. S. (1985). Rental price adjustment and investment in the office market. Journal of the American Real Estate and Urban Economic Association, 13, 32-47.

Hendershott, P. H. (1996). Rental adjustment and valuation in overbuilt markets: Evidence from the Sydney office market. Journal of Urban Economics, 39, 51-67. 
Hendershott, P. H. (1998). Equilibrium models in real estate research: A survey. Journal of Real Estate Literature, 6, 13-25.

Hendershott, P. H., Lizieri, C. M., \& Macgregor, B. D. (2010). Asymmetric adjustment in the city of London office market. The Journal of Real Estate Finance and Economics, 41, 80-101.

Hendershott, P. H., Macgregor, B. D., \& Tse, R. Y. C. (2002). Explaining real commercial rents using an error correction model with panel data. The Journal of Real Estate Finance and Economics, 24, 59-87.

Hendershott, P. H., Macgregor, B. D., \& White, M. J. (2002). Estimation of the rental adjustment process. Real Estate Economics, 30, 165-183.

Ibanez, M. R., \& Pennington-Cross, A. (2013). Commercial property rent dynamics in U.S. metropolitan areas: An examination of office, industrial, flex and retail space. The Journal of Real Estate Finance and Economics, 46, 232-259.

Lee, S. K., \& Jang, S. (2012). Re-examining the overcapacity of the US lodging industry. International Journal of Hospitality Management, 31, 1050-1058.

McCartney, J. (2010). Predicting turning points in the rent cycle using the natural vacancy rate-An applied study of the Dublin office market. Journal of the Statistical and Social Inquiry Society of Ireland, 40, 11-33.

Rosen, K., \& Smith, L. (1983). The price adjustment process for rental housing and the natural vacancy rate. American Economic Review, 73, 779-786.
Shilling, J. D., Sirmans, C. F., \& Corgel, J. B. (1987). Price adjustment process for rental office space. Journal of Urban Economics, 22, 90-100.

Smith, L. B. (1974). A note on the price adjustment mechanism for rental housing. American Economic Review, 64, 478-481.

Tse, R., \& Fischer, D. (2003). Estimating natural vacancy rates in office markets using a time-varying model. Journal of Real Estate Literature, 11, 37-45.

Wheaton, W. C., \& Rossoff, L. (1998). The cyclic behavior of the U.S. lodging industry. Real Estate Economics, 26, 430-436.

Wheaton, W. C., \& Torto, R. G. (1988). Vacancy rates and the future of office rents. Real Estate Economics, 16, 430-436.

Zhou, J. (2008). Estimating natural vacancy rates with unknown break points for the Chicago rental housing market. Journal of Housing Research, 17, 61-74.

\section{Author Biographies}

Bram Gallagher is an economist for CBRE Hotels' Americas Research, producing foreasts of hotel performance and analysis of the hotel market. He was previously an assistant professor of Economics at Middle Tennessee State University and Berry College.

Jack Corgel is a professor of Real Estate in the School of Hotel Administration of the Johnson College of Business at Cornell University. He also serves as an advisor to CBRE Hotels' Americas Research. 